With the peanut preparation evaluated in the present doubleblind trial on 92 haemophiliacs no favourable effect on bleeding could be observed. Based on these findings we would propose to refrain from recommending peanuts or their extracts as a haemostatic agent to haemophilic patients until definite proof of the beneficial effect of a given peanut preparation to the control of haemophilic bleeding is presented.

\section{Summary}

The haemostatic value of an aqueous extract of raw ground and hexane-defatted peanut kernels was evaluated in 92 severely affected haemophilic patients during a six-months double-blind trial. With the criteria selected, no statistical proved benefit on the bleeding incidence could be demonstrated during the "sctive" treatment.
REPERENCES

Astrup T Brakman, P., Ollendorff, P., and Rasmussen, J. (1961) Thrombos. Dial hes. haemorrh. (Stuttg.), $5,329$.

- and Siølin, K.-E. (1962). Nature (Lond.), 194, 980.

Bisordi, M. V. (1964). Lancet, 2, 476.

Boudreaux, H. B. (1967). Personal communication.

Boudreaux, R. M., Brandon, M., Frampton, V. L., and Lee, L. S. (1960). Arch. Biochem., 89, 276.

Brakman, P., Sjolin, K.-E., and Astrup, T. (1962). Thrombos. Diathes. haemorrh. (Stuttg.), 8, 442.

Brüster, H. (1961). Klin. W schr., 39, 1145.

Brüster, (1962). Z. Kinderheilk., 86, 462 .

Cepelák, V. (1965). Z. ges. inn. Med., 20, Suppl. p. 317.

Frampton, V. L., Lee. L. S., Morris, N. J., and Bourdreux, H. B. (1966) Thrombos. Diathes. haemorrh. (Stuttg.), 16, 265.

Jackson, B., Owen, W., and Boudreaux, H. B. (1966). Ibid., 16, 257. Moers, A. M. J., and den Ottolander, G. H. J. (1961). Ned.'T. Geneesk., 105, 2241 .

Nilsson, I. M. (1960). Näringsforsk. Fråg., 4, 66.

Schmutzler, R. (1961). Thrombos. Diathes. haemorrh. (Stuttg.), 5, 566. van Creveld, S., and Mochtar, I. A. (1961). Ann. paediat. (Basel), 197, 1. van Creveld, and Koppe, J. G. (1965). Ibid., 202, 1

Verstraete, M., Vermylen, C., and Devreker, R. (1962). Proceedings of Eighth Congress of European Society of Haematology, Vienna, 1961, comm. 358. Basel.

\title{
Effect of Vagotomy on Gastric Acid Secretion Stimulated by Pentagastrin and Histamine
}

\author{
R. A. PAYNE,* M.S., F.R.C.S. ; ALAN G. COX, $†$ M.D., F.R.C.S.ED. ; JOHN SPENCER, $\ddagger$ M.B., B.S., F.R.C.S. \\ F. C. Y. CHENG, $\S$ M.B., B.S., F.R.C.S., F.R.C.S.ED.
}

Brit. med. F., 1967, 4, 456-457

The study of human gastric acid secretion has been hindered by lack of a readily available agent which has the properties of gastrin and which can be administered to man with safety. Hog antral mucosa has provided a source of gastrin for animal experimentation, but until isolated in a pure form by Gregory and Tracy (1964) gastrin has not been available for use in man. The production of pure gastrin on a commercial scale has not proved practicable. However, since the introduction of a synthetic substance known as pentagastrin (Peptavlon, I.C.I.) the physiological properties of gastrin can be studied. This is a pentapeptide with a terminal tetrapeptide which appears to be the physiologically active constituent of gastrin (Tracy and Gregory, 1964).

The present investigation was undertaken to compare the effect of vagotomy (with pyloroplasty) on the maximal gastric responses to stimulation by histamine and by pentagastrin. Histamine has been widely used to study acid secretion, but it may now be superseded by pentagastrin. It is therefore important to determine if the results of investigations with pentagastrin can be compared with those of previous work with histamine.

\section{Method of Study}

Fifteen patients with uncomplicated chronic duodenal ulcer were studied before and after total vagotomy with pyloroplasty. Before operation the maximal acid responses to histamine and to pentagastrin were measured on two separate days. Seven to 10 days after operation an insulin test was performed to confirm the completeness of vagotomy, and the two tests with

* Consultant Surgeon, North Middlesex Hospital, London N.18 ; Honorary Lecturer in Surgery, Royal Postgraduate Medical School, London ary L. L.

t Lecturer in Surgery, Royal Postgraduate Medical School ; Consultant Surgeon, Hammersmith Hospital, London W.12.

Tutor in Surgery, Royal Postgraduate Medical School ; Senior Registrar, Hammersmith Hospital, London W.12.

Honorary Registrar. Hammersmith Hospital ; Lecturer in Surgery, University of Hong Kong. histamine and pentagastrin were then repeated on successive days.

All secretory tests were carried out in the morning after an overnight fast. Before operation a 16 French gauge nasogastric tube was passed into the most dependent part of the stomach under $x$-ray control. In the postoperative tests use was made of a double-lumen feeding gastrostomy tube for collection of the gastric secretions. The tube was placed at operation with one limb in the dependent part of the stomach and the other in the duodenum (Burns and Menzies, 1966). In all tests gastric juice was aspirated continuously by an electric pump at a subatmospheric pressure of $5 \mathrm{~cm}$. $\mathrm{Hg}$, and the patency of the tube was checked at frequent intervals throughout each test. The aspirations were collected in 15-minute samples and their total acid content in $\mathrm{mEq}$ was measured by titration with

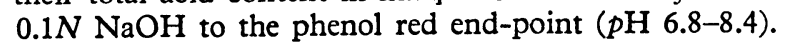

In each test two 15-minute specimens of basal secretion were collected after aspiration of the fasting juice. The tests then continued as follows:

Maximal Histamine Response.-Histamine acid phosphate was infused intravenously at a rate of $40 \mu \mathrm{g} . / \mathrm{kg}$./hour (Lawrie et al., 1964) for 120 minutes. The maximal response was taken as the sum of the four consecutive samples giving the highest total.

Maximal Pentagastrin Response.-Pentagastrin was infused intravenously at a rate of $6 \mu \mathrm{g} . / \mathrm{kg} . /$ hour for 90 minutes, which is sufficient to give a steady level of secretion (Multicentre Pilot Study, 1967). The maximal response was calculated as for the histamine test.

Insulin Test.-Soluble insulin, $0.25 \mathrm{unit} / \mathrm{mg}$., was injected in a single intravenous dose and completeness of vagotomy was accepted if the concentration of acid in the next two hours failed to rive by more than $20 \mathrm{mEq}$ /litre above the basal concentration.

\section{Results}

Table I shows the maximal response to histamine and pentagastrin before and after vagotomy in each patient. All 15 patients showed a substantially reduced response to boih 
agents after vagotomy. The reduction in the response due to vagotomy is usually expressed as a percentage of the preoperative value, and the result of this calculation is shown for each patient in Table II. The mean reduction in the histamine response $(66.4 \%)$ does not differ significantly from the mean reduction in the pentagastrin response $(61.5 \%)$. The correlation between the two reductions is shown in the Chart and is statistically significant $(P<0.001)$.

Some of our results with pentagastrin formed part of an investigation into the effects of vagotomy on gastric acid secretion elicited by pentagastrin (Multicentre Study, 1967).

TABLB 1.-Maximal One-hour Gastric Acid Secretion in Response to Intravenous Histamine and Intravenous Pentagastrin Before and After Total Vagotorny

\begin{tabular}{c|c|c|c|c}
\hline \multirow{2}{*}{$\begin{array}{c}\text { Case } \\
\text { No. }\end{array}$} & \multicolumn{4}{|c}{ Maximal Gastric Acid Secretion (mEq/hour) } \\
\cline { 2 - 5 } & \multicolumn{2}{|c|}{ Before Vagotomy } & \multicolumn{2}{|c}{ After Vagotomy } \\
\cline { 2 - 5 } & Histamine & Pentagastrin & Histamine & Pentagastrin \\
\hline 1 & 49.3 & 46.3 & 13.8 & 13.0 \\
2 & 25.4 & 41.5 & 3.8 & 9.5 \\
3 & 36.3 & 27.8 & 19.4 & 18.5 \\
4 & 36.7 & 32.0 & 1.9 & 0.5 \\
5 & 34.9 & 34.6 & 4.6 & 3.2 \\
6 & 28.1 & 28.1 & 16.1 & 18.4 \\
7 & 13.7 & 23.1 & 8.8 & 18.4 \\
8 & 26.6 & 35.2 & 12.9 & 21.3 \\
9 & 59.2 & 51.8 & 36.7 & 19.8 \\
10 & 46.5 & 47.2 & 26.1 & 26.9 \\
11 & 40.8 & 63.7 & 27.0 & 39.1 \\
12 & 43.9 & 40.1 & 7.9 & 10.6 \\
13 & 19.2 & 48.9 & 6.2 & 8.0 \\
14 & 29.0 & 35.9 & 1.3 & 8.0 \\
15 & 35.5 & 38.8 & 1.7 & 1.6 \\
\hline Mean & 12.1 & 11.3 & 12.6 & 14.4 \\
S.D. & & & 10.7 & 10.3 \\
\hline
\end{tabular}

TABLE II.-Percentage Reduction in Maximal Gastric Acid Secretion After Vagotomy in Response to Intravenous Histamine and Intravenous Pentagastrin

\begin{tabular}{c|c|c}
\hline \multirow{2}{*}{ Case No. } & \multicolumn{2}{|c|}{ \% Reduction in Maximal Acid Secretion after Vagotomy } \\
\cline { 2 - 3 } & Histamine Stimulation & Pentagastrin Stimulation \\
\hline 1 & 72 & 72 \\
2 & 85 & 77 \\
3 & 49 & 32 \\
4 & 95 & 98 \\
5 & 87 & 91 \\
6 & 50 & 35 \\
7 & 36 & 20 \\
8 & 52 & 39 \\
9 & 38 & 62 \\
10 & 44 & 43 \\
11 & 35 & 38 \\
12 & 80 & 74 \\
13 & 86 & 69 \\
14 & 93 & 96 \\
15 & 94 & 61.9 \\
\hline Mean & 66.4 & 25.5 \\
S.D. & 23.4 & \\
\hline
\end{tabular}

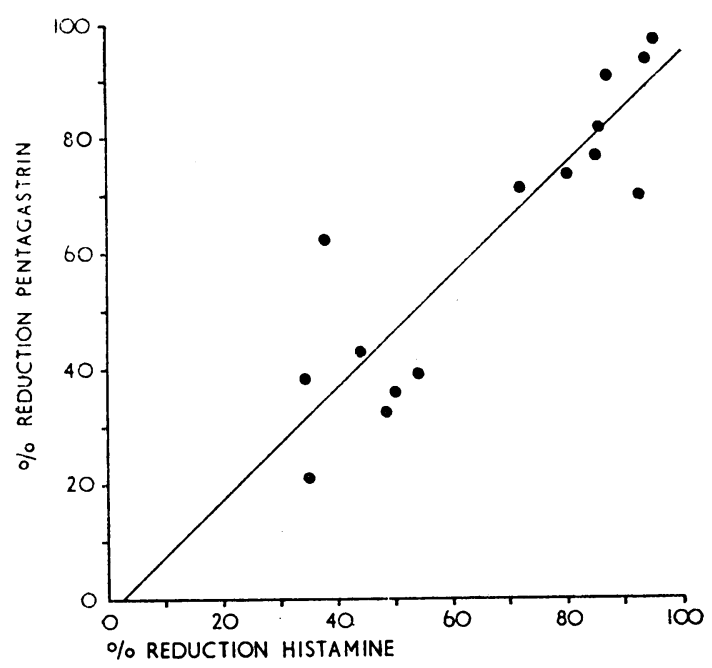

Correlation of percentage reduction after vagotomy of Pentagastrin- and histamine-stimulated maximal gastric acid Pentagastrin- and histamine-stimulated maximal gastric acid
secretion. The correlation coefficient is $+0.89(\mathrm{P}<0.001)$ secretion. The correlation coefficient is $+0.89(P<0.001)$
The equation for the regression line is $y=0.968 x \pm 2.37$.

\section{Discussion}

This investigation shows that vagotomy reduces the maximal gastric acid secretory response to pentagastrin and to histamine by similar proportions. A similar finding has been reported by Jepson and Johnston (1967) in a study of the effects of vagotomy on Histalog- (ametazole hydrochloride) and pentagastrinstimulated acid secretion. Their observations contrast with the results of a previous study from this centre (Barabas et al., 1966) in which a hog antral mucosal extract of gastrin (Leo) was used instead of pentagastrin. In that study the reduction in acid secretion after vagotomy was $60 \%$ with histamine and only $33 \%$ with the mucosal extract. A similar observation has been made by Weir et al. (1966). Bank et al. (1967), in a study of patients after vagotomy, state that the pentagastrin response is greater than the histamine response. The implication that the pentagastrin response is reduced less than the histamine response was not substantiated, since no tests with pentagastrin were carried out before vagotomy. In a Multicentre Study (1967) of the effects of vagotomy on the maximal acid secretory response to pentagastrin a mean reduction of $62 \%$ was found after vagotomy, but measurements of histamine-stimulated acid secretion were not made.

Comparison of the results of our earlier study (Barabas et al., 1966) and the present one suggests a difference between the properties of the synthetic pentapeptide and the mucosal extract. This is supported by the work of Neely (1967), who made a direct comparison of the effect of these two agents on alimentary motility and found a difference in the response of the small intestine. Our present results with pentagastrin conform more closely with the observation of Welbourn and Burns (1964) that vagotomy in man reduced by $67 \%$ the acid output to endogenous gastrin after perfusion of the stomach with a meal extract.

Unlike histamine, pentagastrin has minimal side-effects and seems likely to supersede it in the measurement of gastric acid secretion. Our present study allows the practical conclusion that the results with pentagastrin are closely comparable to those following histamine stimulation both before and after vagotomy.

\section{Summary}

Maximal gastric acid secretion in response to intravenous infusions of pentagastrin (Peptavlon) and histamine has been measured before and after complete surgical vagotomy in 15 patients with chrontc duodenal ulcer. After vagotomy the response to both stimulants was reduced by similar proportions.

We wish to express our appreciation to the following: Professor R. B Welbourn for advice and encouragement; Staff Nurses Alexander, Sherman, and Pope and Mrs. Vedast for help with the tests ; thı: N.E. Metropolitan Regional Hospital Board for a research grant (R. A. P.) ; and I.C.I. for supplies of Peptavlon and the salary of a tectnician (A. G. C.).

\section{REFERENCES}

Bank, S., Marks, I. N., Louw, J. H., and Tigler-Wybrandi, N. (1967). Lancet, 2, 67.

Barabas, A. P. Payne, R. A., Johnston, I. D. A., and Burns, G. P. (1966). Ibid., 1, 118.

Burns, G. P., and Menzies, T (1966). Brit. J. Surg., 53, 433.

Gregory, R. A., and Tracy, H. J. (1964). Gut, 5, 103.

Jepson, K., and Johnston, D (1967) Paper to July Meeting of the Surgical Research Society at Aberdeen.

(1964). Lancet, 2, 270 .

Multicentre Pilot Study (1967). Ibid. 1, 291.

Multicentre Pilot Study (1967). Ibid,

Neely, J. (1967). Gut, 8, 242.

Neely, (1967). Gut, 8, 24. R. (1964). Nature (Lond.), 204, 935.

Tracy, H. J., and Gregory. R. A. (1964). D. (1966). Gut, 7. 710.

Welbourn, R. B., and Burns, G. P. (1964). Congress of International Gastroenterology, 1, 163. 